\title{
Granulomatous enteropathy in common variable immunodeficiency: a cause of chronic diarrhoea
}

\author{
N. Mike, T.T. Hansel, J. Newman and P. Asquith \\ Departments of Gastroenterology, Immunology and Histopathology, East Birmingham Hospital, Bordesley \\ Green East, Birmingham B9 5ST, UK.
}

Summary: Gastrointestinal disease is a well recognized feature in patients with common variable immunodeficiency, and is often due to infection with a variety of organisms. Symptoms usually improve with appropriate antibiotic therapy and replacement gammaglobulin. We describe three middle-aged female patients with common variable immunodeficiency who had protracted diarrhoea and weight loss. Despite extensive investigation no infectious cause was found.

All patients had granulomas distributed throughout the gastrointestinal tract, but no features of inflammatory bowel disease. There was a poor response to gammaglobulin replacement therapy, antibiotics or symptomatic treatment. We suggest that granulomatous enteropathy is another gastrointestinal manifestation of common variable immunodeficiency.

\section{Introduction}

A large number of gastrointestinal manifestations are recognized in patients with common variable immunodeficiency (acquired hypogammaglobulinaemia), and form a major component of the condition. ${ }^{1-4}$ These include infectious complications such as giardiasis, small intestinal bacterial overgrowth and bacterial and viral enteritis. Gastritis, pernicious anaemia and gastric malignancy are well recognized complications. ${ }^{4}$ Nodular lymphoid hyperplasia is found in $20-60 \%$ of these patients, and other associations include hypogammaglobulinaemic sprue and ulcerative jejunitis. We describe three patients with common variable immunodeficiency and chronic gastrointestinal symptoms in whom a granulomatous enteropathy was found.

\section{Case reports}

Case 1

A 55 year old female had recurrent infections over a period of 25 years with episodes of pneumonia, and the latter had resulted in bronchiectasis. In 1973 she was found to have panhypogammaglobulinaemia (IgG $0.22 \mathrm{~g} / 1, \mathrm{IgA}$ and IgM not detected). Delayed hypersensitivity skin tests to recall antigens were negative and lymphocyte transformation studies

Correspondence and present address: N. Mike, M.D., M.R.C.P., Stoke Mandeville Hospital, Aylesbury, Buckinghamshire HP21 8AL, UK.

Accepted: 30 August 1990 gave subnormal responses. Common variable immunodeficiency was diagnosed ${ }^{5}$ and treatment $\vec{\theta}$ started with weekly intramuscular gammaglobulg $\triangleq$ and postural drainage.

She remained well until 1984 when asympte matic hypercalcaemia was noted, with corrected calcium $2.88 \mathrm{mmol} / 1$ (normal $2.33-2.66 \mathrm{mmol} / \mathrm{l}$ ). Parathyroid hormone levels have repeatedly been $\%$

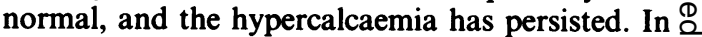
1986 she developed extensive erythema nodosum $\overrightarrow{\vec{O}}$ which lasted 4 months. Chest X-ray showed bron- $\frac{3}{3}$ chiectasis but no features of sarcoidosis. Angioten- $\bar{P}$ sin converting enzyme was not elevated and a Kveim test was negative.

At this stage the patient developed diarrhoea lasting for 9 months, during which time she lost $10 \mathrm{~kg}$ in weight. Immunoglobulin levels were satisfactory on replacement therapy. Tests of poly- $\bigcirc$ morph function (nitroblue tetrazolium reduction following phorbol myristic acetate stimulation) 옹 gave normal responses. No organisms were iso- $\rightarrow$ lated or grown from numerous faecal and jejunal aspirate specimens. Tests of absorption were nor- $\bar{N}$ mal, and there was no steatorrhoea. Flexible sigmoidoscopy revealed normal looking bowel $\tilde{O}$ mucosa. On rectal biopsy (Figure 1) the gland $\underset{\omega}{N}$ architecture was mildly distorted and there were non-caseating granulomata including giant cells. $\bullet$ Barium enema demonstrated a normal appearance $\bar{\varnothing}$ of the colon and terminal ileum. At endoscopy the ?+? upper gastrointestinal tract looked normal. Duo- $T$ denal biopsy had a normal villous pattern but an

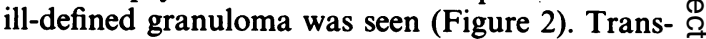
bronchial biopsy showed normal lung parenchyma $\stackrel{\mathbb{D}}{\varrho}$ 


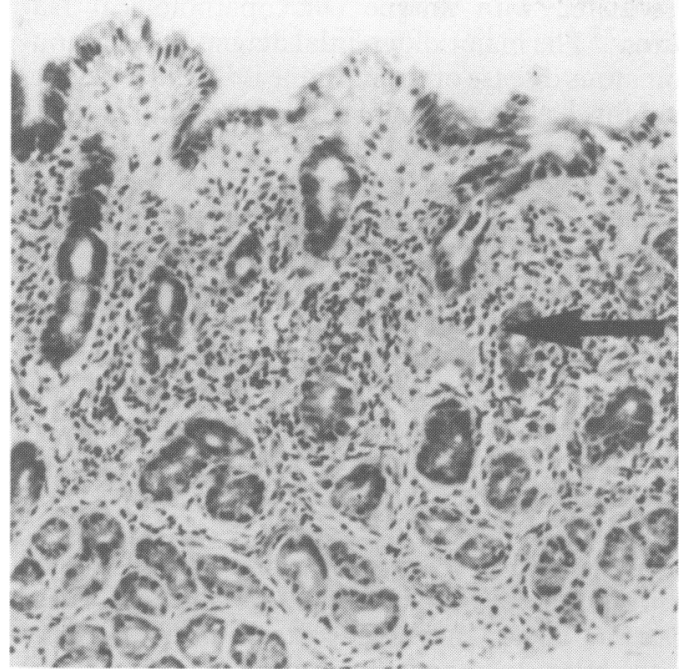

Figure 1 Gastric pyloric mucosa. The arrow indicates a small granuloma. H\&E $\times 100$.

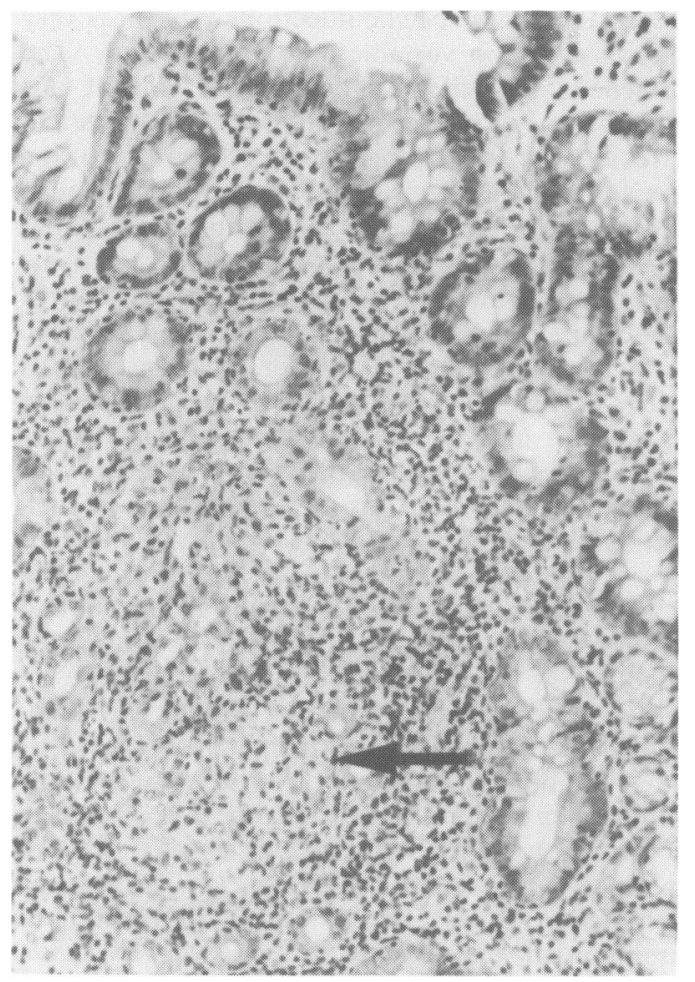

Figure 2 Duodenal mucosa. The arrow indicates an epithelioid cell granuloma. H\&E $\times 100$. with acute and chronic inflammatory cells and occasional giant cells in the bronchial mucosa. Symptoms slowly improved with anti-diarrhoeal agents and dietary supplements, though she remains underweight.

\section{Case 2}

This 35 year old housewife developed persistent diarrhoea in 1975 with weight loss of $16 \mathrm{~kg}$. Over the next 2 years she had recurrent chest, ear and sinus infections. There was vitiligo and splenomegaly on examination. Investigations revealed panhypogammaglobulinaemia (IgG $0.2 \mathrm{~g} / \mathrm{l}$, IgA and IgM undetectable) and treatment with intramuscular gammaglobulin was started. Despite this the diarrhoea continued 3-4 times daily and she failed to gain weight. Further investigation showed no evidence of malabsorption or a protein losing enteropathy. Stool cultures were repeatedly negative and no organisms were seen or cultured from a jejunal aspirate. Jejunal biopsy was histologically normal. Serum B12 was very low at $8 \mathrm{ng} / \mathrm{l}$ (normal $150-800 \mathrm{ng} / \mathrm{l})$ with megaloblastic erythropoiesis and treatment with hydroxycobalamin was commenced. No gut pathogens were isolated despite extensive testing. By 1986, as well as the diarrhoea, she complained of abdominal pain and vomiting. At endoscopy the upper gastrointestinal tract looked normal. However, biopsy of the stomach demonstrated a few non-caseating granulomata including giant cells within the lamina propria (Figure 3). No acid-fast bacilli were seen. There was no evidence of sarcoidosis and polymorph function tests were normal. Symptomatic treatment with antiemetics, antidiarrhoeal agents and dietary supplements have caused little improvement.

\section{Case 3}

This 46 year old woman had attacks of severe abdominal pain associated with marked diarrhoea (20-30 times in 24 hours) for 6 years. These episodes lasted about 1 week and recurred every 3 months. Endoscopy, barium enema and sigmoidoscopy revealed no cause for her symptoms. She had a panhypogammaglobulinaemia: IgG $1.85 \mathrm{~g} / \mathrm{l}, \mathrm{IgA} 0.45 \mathrm{~g} / \mathrm{l}$, IgM $0.25 \mathrm{~g} / \mathrm{l}$. Lymphocyte transformation responses were impaired and common variable immunodeficiency was diagnosed. A barium follow-through showed nodular lymphoid hyperplasia in the jejunum.

She was commenced on intramuscular gammaglobulin replacement following an episode of whooping cough. She was asymptomatic on this until 1988 when she developed sinusitis and an anaerobic lung abscess which responded to tinidazole and erythromycin. Intravenous immunoglobin was commenced. In 1989 she had diarrhoea 


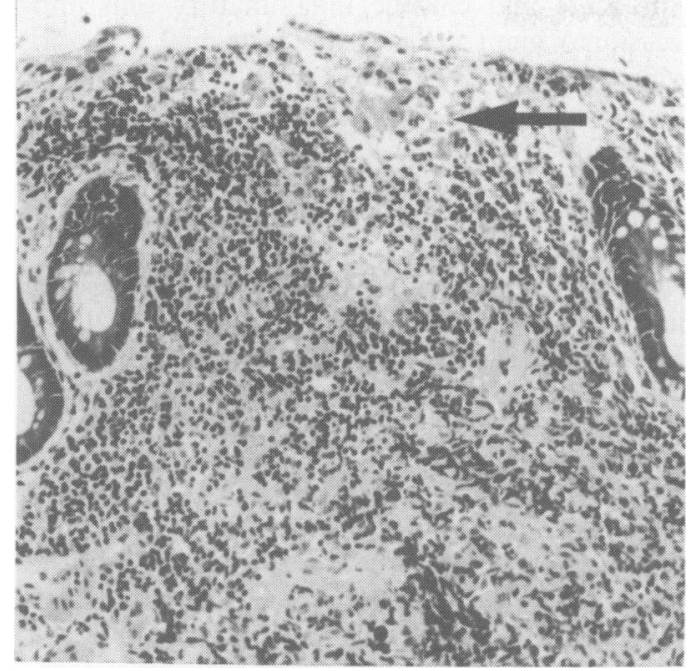

Figure 3 Colonic mucosa. The arrow indicates an illformed epithelioid granuloma just beneath the surface epithelium. H\&E $\times 100$.

for 8 months, accompanied by erythema nodosum. No infectious cause was found for this. A hydrogen breath test showed normal intestinal transit with no evidence of small intestinal bacterial overgrowth. At flexible sigmoidoscopy there were at least 10 small nodules, $2-3 \mathrm{~mm}$ in diameter, in the rectum and sigmoid colon. Histology of these lesions showed an altered glandular pattern with a patchy increase in mononuclear inflammatory cells. An ill-defined focus of epithelioid cells, without giant cells, was seen. There were no features of nodular lymphoid hyperplasia. At endoscopy no abnormality was seen in the stomach or duodenum. However, histological examination revealed ill-defined granulomas and giant cells in the gastric mucosa. Duodenal biopsies were normal. A prolonged course of therapy with metronidazole and erythromycin had no effect on her gastrointestinal symptoms which have persisted.

\section{Discussion}

These three patients with common variable immunodeficiency have had a protracted diarrhoeal illness with weight loss. None of the recognized infective causes or other gastrointestinal manifestations of hypogammaglobulinaemia ${ }^{1,2}$ were found to account for this, though the first patient had concurrent pernicious anaemia and the third had nodular lymphoid hyperplasia, both common in this disease. ${ }^{4}$ All three patients had granulomas in the gastrointestinal tract, requiring careful scrutiny at multiple levels to identify, and associated with unique clinicopathological features. ${ }^{7,8}$ The major differential diagnosis for granulomatous disease of the intestine is Crohn's disease, and this has occasionally been reported in patients $\stackrel{8}{2}$ with common variable immunodeficiency. ${ }^{9-11} .$. These patients had typical features of Crohn's $\overrightarrow{\vec{F}}$ disease with strictures in the small and large $\stackrel{?}{+}$ intestine resulting in intestinal obstruction. The inflammation was transmural with granuloma formation. None of the three patients described here has any definite radiological or endoscopic features of Crohn's disease. An uncommon cause of intestinal granulomas and recurrent infections is $\overrightarrow{0}$ chronic granulomatous disease ${ }^{12}$ exluded in our patients by virtue of normal nitroblue tetrazolium tests.

A sarcoid-like syndrome occurs in some patients with common variable immunodeficiency. ${ }^{1,13}$ These patients have a reticular pattern on chest X-ray with hilar lymphadenopathy and reduced gas transfer. Non-caseating granulomas are found in the lungs, liver, spleen and skin, but gastrointestinal involvement is not described in this condition. ${ }^{14}$ The Kveim test is negative in the presence of active disease, and the condition is considered to be different from true sarcoidosis. Erythema nodosum, however, is a well recognized finding in sarcoidosis, and also in inflammatory bowe disease and with specific infections, ${ }^{15}$ but it is ver rare in common variable immunodeficiency. The presence of erythema nodosum in two of out patients suggests some similarities with classical sarcoidosis. On the other hand involvement of the gastrointestinal tract in association with active sarcoidosis is very rare ${ }^{16,17}$ Diarrhoea and weight loss are the presenting symptoms and these patients may have jejunal villus atrophy with malabsorption and non-caseating granulomas in the small and large intestine. ${ }^{18}$ However, true sarcoidosis with a positive Kveim test, raised angiotensin convertase level, and response to steroids is extremely uncommon in patients with hypogammaglobulinaemia. ${ }^{19}$ Steroids have been used in such patients with the sarcoid-like syndrome and pulmonary involvement, and have had a beneficial effect both on symptoms, impaired gas transfer and radiological changes. ${ }^{1-14}$ This treatment was not used in the three patients described because an infectious cause was suspected (though not identified) for their gastrointestinal symptoms.

Granuloma formation can be an immune mechanism against poorly degradable or poorly soluble substances including a large variety of micro-organisms. ${ }^{12}$ A number of such organisms commonly cause gastrointestinal infection in immunodeficient patients, including Giardia lamblia, cryptosporidium, rotavirus, as well as the more usual intestinal organisms. ${ }^{1,2,20}$ In particular, campylobacter enteritis may have a prolonged clinical 
course, and be difficult to eradicate with antibiotics. ${ }^{4,21}$ A hypogammaglobulinaemic patient has been described in whom chronic campylobacter infection was associated with granulomas on rectal biopsy. ${ }^{22}$ In two further hypogammaglobulinaemic patients with chronic diarrhoea and mild steatorrhoea, rod-shaped organisms were isolated from the stools which reacted with an antiserum raised against Campylobacter jejuni. ${ }^{4}$ This organism could not be cultured in vitro, suggesting that the diarrhoea may have been due to a previously unrecognized campylobacter.

Finally, a single patient has been described with malakoplakia of the colon complicating acquired hypogammaglobulinaemia. ${ }^{23}$ This disease is quite distinct from the granulomatous lesions found in the three patients described here. We suggest that the granulomatous enteropathy is a novel gastro- intestinal manifestation of common variable immunodeficiency. It is important to recognize because of its morbidity and its poor response to therapy such as prolonged antibiotic treatment. Particularly striking is the lack of improvement with intravenous gammaglobulin. The finding of this enteropathy in three patients with common variable immunodeficiency in this centre suggests that this disorder may not be uncommon in such patients. The underlying cause, which may be infectious, remains to be elucidated.

\section{Acknowledgements}

We are grateful to Dr R.A. Thompson for permission to report on patients under his care, and to Ms Tracey Green and Mrs Karen Platt for typing the manuscript.

\section{References}

1. Asherson, G.L. \& Webster, A.D.B. Gastrointestinal tract in hypogammaglobulinaemia. In: Diagnosis and Treatment of Immunodeficiency Diseases. Blackwell Scientific Publications, Oxford, 1980, pp. 61-77.

2. Ross, I.N. Primary immunodeficiency and the small intestine. In: Marsh M.N. (ed.) Immunopathology of the Small Intestine. John Wiley and Sons, Chichester, 1987, pp. 283-332.

3. Sperber, K.E. \& Mayer, L. Gastrointestinal manifestations of common variable immunodeficiency. Immunol Allergy Clin North Am 1988, 8: 423-434.

4. Webster, A.D.B. Immunodeficiency and the gut. Bailliere's Clinical Gastroenterology, Vol. 1. Bailliere Tindall, London, 1987, pp. 547-565.

5. Rosen, F.S., Wedgewood, R.J., Auti, F. et al. Primary immunodeficiency diseases. Report prepared for WHO by a scientific group on immunodeficiency. Clin Immunol Immunopathol 1983, 28: 450-475.

6. Webster, A.D.B. Laboratory investigations of primary deficiency of the lymphoid system. Clin Immunol Allergy 1985, 3: 447-467.

7. Hermans, P.E., Diaz-Buxo, J.A. \& Stobo, J.D. Idiopathic late onset immunoglobulin deficiency: clinical observation in 50 patients. Am J Med 1976, 61: 221-237.

8. Ament, M.E., Ochs, H.D. \& Davis, S.D. Structure and function of the gastrointestinal tract in primary immunodeficiency syndrome; a study of 39 patients. Medicine 1973 , 53: $227-248$.

9. Eggert, R.C., Wilson, I.D. \& Good, R.A. Regional enteritis. Ann Intern Med 1969, 71: 581-585.

10. Soltoft, J., Petersen, L. \& Kruse, P. Immunoglobulin deficiency and regional enteritis. Scand J Gastroenterol 1972, 7: 233-236.

11. Fillit, H., Bernstein, L., Davidson, M., Brandt, L., Bezahler, G. \& Cohen, M. Primary acquired hypogammaglobulinaemia and regional enteritis. Arch Intern Med 1977, 137: 1252-1254.

12. Weinstock, J.V. Immunoregulation of granulomatous inflammation in the liver and intestines. In: Marsh, M.N. (ed.) Immunopathology of the Small Intestine. John Wiley, Chichester, 1987, pp. 151-175.
13. Sharma, O.P. \& James, D.G. Hypogammaglobulinaemia, depression of delayed type hypersensitivity and granuloma formation. Am Rev Resp Dis 1971, 104: 228-231.

14. Friedman, R., Ackerman, M., Mallory, G., Weng, T.R. \& Fireman, P. Hypogammaglobulinaemia with sarcoid-like granulomas. Am J Dis Child 1983, 137: 774-776.

15. Rook, A., Wilkinson, D.S., Ebling, F.J.G., Champion, R.H. \& Burton, J.L. (eds) Textbook of Dermatology, Fourth Edition. Blackwell Scientific Publications, Oxford, 1986, pp. 1156-1165.

16. Gould, S.R., Handley, A.J. \& Barnardo, D.E. Rectal and gastric involvement in a case of sarcoidosis. Gut 1973, 14: 970-973.

17. Konda, J., Ruth, M., Sassaris, M. \& Hunter, F.M. Sarcoidosis of the stomach and rectum. Am J Gastroenterol 1980, 73: 516-518.

18. Sprague, R., Harper, P., McClain, S., Trainer, T. \& Beeken, W. Disseminated gastrointestinal sarcoidosis. Case report and review of the literature. Gastroenterology 1984, 87: 421-425.

19. Lee, C.A. Acquired hypogammaglobulinaemia and sarcoidosis. Postgrad Med J 1984, 60: 551-553.

20. Haeney, M. Immunodeficiency. In: Losowsky, M.S. \& Heatley, R.V. (eds) Gut Defences in Clinical Practice. Churchill Livingstone, London, 1986, pp. 278-298.

21. Henochowicz, S. Chronic diarrhoea and weight loss in patient with chronic variable immunodeficiency. Ann Allergy 1986, 56: 382-383, 410-413.

22. Green, E.S., Parker, N.E., Gellert, A.R. \& Beck, E.R. Campylobacter infection mimicking Crohn's disease in an immunodeficient patient. Br Med J 1984, 289: 159-160.

23. Mir-Madjlessi, S.H., Tavassolie, H.\& Kamalian, N. Malakoplakia of the colon and recurrent colonic strictures in a patient with primary hypogammaglobulinaemia. Dis Colon Rectum 1982, 25: 723-727. 